\title{
AUTONOMIA COMO FUNDAMENTO DA DEMOCRATIZAÇÃO DA DEMOCRACIA: ALGUMAS FERRAMENTAS TEÓRICAS DO SPINOZISMO
}

\section{Thais Florencio de Aguiar ${ }^{1}$}

\begin{abstract}
Resumo: Este trabalho pretende apresentar alguns elementos da teoria de Spinoza que possibilitem pensar a noção de autonomia, noção essa considerada indissociável, e mesmo constitutiva, da experiência de democracia, isto é, do processo contínuo de democratização ou radicalização da democracia. Como aponta Castoriadis, é por meio da compreensão da autonomia que se explicita a perspectiva de que as sociedades são normalmente edificadas sobre a base da ocultação de sua auto-instituição, compreensão essa que possibilita estabelecer a instauração de uma sociedade autônoma em seu movimento democrático. Além de constituir elementos teóricos em dissonância com teorias mais hegemônicas na tradição moderna (o kantismo, o liberalismo), o spinozismo fornece ferramentas para se pensar um projeto de autonomia não como um problema estritamente filosófico ou epistemológico, e sim, político e social. Entende-se que noções como razão afetiva e relacional, transindividualidade da multidão, sui juris, bem como de direito de guerra e de indignação (mecanismos autorreguladores do corpo social) apresentam ferramentas teóricas que sugerem uma subsunção da noção de autonomia. Concebida a partir de uma espécie de dependência originária, essa autonomia, ou melhor, autonomização/libertação não designa indivíduos autônomos como independentes.
\end{abstract}

Palavras-chave: Autonomia. Democracia. Spinozismo.

\section{INTRODUÇÃO²}

"Por otro lado, desde quienes reivindicamos la autonomía, pareciera haber una comprensión multidimensional, compleja y polisémica del significado de ella, que va desde la independencia de la clase política y sus partidos, hasta una forma organizativa de los pueblos indios; desde una forma de expresión de la protesta

1 Doutora em Ciência Política. Pesquisadora e professora em pós-doutoramento no Instituto de Estudos Sociais e Políticos (IESP) da Universidade do Estado do Rio de Janeiro (UERJ), pesquisadora do Grupo de Pesquisa Anticapitalismos e Sociabilidades Emergentes (GPASE).

2 O tema deste ensaio é um desdobramento de pesquisa de doutoramento e, nessa medida, resgata em alguns momentos formulações desenvolvidas nesse trabalho anterior (AGUIAR, 2015). 
social hasta la posibilidad de la autorregulación generalizada de distintas colectividades. Esta rica discusión significa para nosotras y nosotros una reflexión primordial, no en el sentido académico, teórico o abstracto sobre las autonomías, sino un debate decisivo para la acción política hoy, para el sentido del cambio social, de la transformación radical, e incluso, de las alternativas civilizatorias al capital y al Estado."

(Jovens en resistencia alternativa. Pensar las autonomías, p. 10)

"Nada é mais insuportável aos homens que ser submetidos a seus iguais e de ser dirigidos por eles."

(Spinoza, TTP V, 8)

A democracia moderna tem se apresentado, em vários aspectos, como uma experiência heterônoma, sobretudo, para as vastas camadas populares da sociedade, as que sofrem diretamente com a manutenção da desigualdade e da opressão. As críticas ao sistema representativo, acompanhadas do crescimento da deserção eleitoral e mesmo do fortalecimento do discurso de exaltação de medidas antidemocráticas, são apenas sintomas de insatisfação e de impotência experimentada na democracia. Esses sintomas têm raízes mais profundas do que sugerem, às vezes, a análise conjuntural. Elas estão localizadas nos fundamentos teóricos da democracia vista como regime, e se manifestam em seu conteúdo não só formal-racional (mecanismos e práticas eleitorais, institucionais) como também ético-político (princípios, ideais e utopias). Em um cenário em que grassa a conjunção de liberalismo e capitalismo em detrimento patente da democracia, esses conteúdos estão em constante disputa e determinam o próprio significado desta forma de governo.

A elaboração de uma concepção de autonomia como fundamento político tem como ponto de partida a compreensão de uma necessidade de democratização ou radicalização da democracia. Cada vez mais reduzida a aparatos, protocolos e procedimentos, a democracia moderna ou contemporânea (em contraste com a antiga) ganhou moldes minimalistas, hoje em largo processo de retraimento, de freio ou bloqueio de impulsos por democratização substantiva. De certo modo, pode-se dizer que se vive tempos de experimentação de impotência e de mal-estar, em que os indivíduoscidadãos sentem-se sujeitos a uma lei exterior superior, ao mesmo tempo não se reconhecem como agentes ou operadores da política que os conduzem e da qual padecem. Essa é uma das faces mais desconcertantes da condição de heteronomia.

De acordo com essa perspectiva, este ensaio pretende apresentar alguns 
elementos teóricos que ajudem a pensar parte do conteúdo ético-político, a saber, o princípio da autonomia, considerado indissociável, e mesmo constitutivo, da experiência democrática, do processo contínuo de democratização ou radicalização da democracia. Aqui o referencial teórico é a obra de Castoriadis, autor que dedicou toda uma vida intelectual na construção de um projeto de autonomia. Como formula, as sociedades são normalmente edificadas sobre a base da ocultação de sua auto-instituição.

Retomar o tema da autonomia como agenda de pesquisa permite lançar luz sobre essa condição de passividade. Sendo o demos (a multidão de pobres) o mais numeroso, por que vigora a experiência da impotência? Se a sociedade é auto-instituinte, por que os indivíduos que dão carne a essa sociedade se sentem passivos? Por que se apresentam como joguete das circunstâncias que os ultrapassam? Por que impera a visão de que a experiência democrática se caracteriza por pura contingência, bem distante da autodeterminação ou do autogoverno característico da condição autônoma? Ainda inspirados em La Boétie, pergunta-se por que os indivíduos são conduzidos a experimentar a maior parte do tempo uma espécie de servidão voluntária, sendo vítimas ao mesmo tempo em que algozes? Tantas questões. Difícil encontrar respostas, possível identificar pistas. Vale ressaltar que o traço forte da heteronomia que caracteriza a sociedade democrática permanece sendo a divisão social entre expropriados e expropriadores, dominados e dominantes, todos fazendo parte de uma mesma deriva.

Diante desse emaranhado de questões, parece cada vez mais candente a tarefa para qual se dirigiu o pensamento de Castoriadis ao final do século XX, qual seja, a de buscar instaurar uma sociedade autônoma em seu movimento democrático. Trata-se de entender o movimento democrático como o próprio construir dessa autonomia. Para isso, é preciso ter em mente qual o sentido e o significado de um projeto de autonomia como princípio de democratização.

No curso deste ensaio, situa-se brevemente a abordagem do conceito de autonomia. Em seguida, elencam-se alguns elementos da teoria política do filósofo Spinoza que se associem ao conceito ou permitam iluminá-lo. Por apresentar certas noções antípodas de boa parte da tradição moderna, o spinozismo fornece ferramentas para se pensar a autonomia não como um problema estritamente filosófico ou epistemológico, e sim, político e social. Tentamos averiguar em que medida algumas noções produzidas pelo spinozismo constituem instrumentos teóricos que subsumem a noção de autonomia, como sua visão acerca dos gêneros de conhecimento, a concepção 
de indivíduo como abstração de um mundo transindividual, o uso do binômio sui juris/alterius juris, bem como a validação do direito de guerra e da indignação como mecanismos autorreguladores do corpo social.

Este ensaio constitui o esforço de investigação inicial que integra o projeto de pesquisa mais amplo sobre concepções acerca de um projeto de autonomia ou de libertação para intensificação ou radicalização da democracia. Nele, estão englobadas também teorias de correntes libertárias (socialismo, anarquismo, comunismo), além das marxistas heterodoxas, que produzem concepções capazes de consubstanciar um projeto de autonomia como princípio e fundamento da democratização, na medida em que essas vertentes disputam o significado da reinvenção moderna da democracia. Assim o fazem, conjugando essa disputa com a resistência ao capitalismo no século XIX e produzindo repertórios e formulações dissociados do liberalismo. Dessa forma, tenta-se desvencilhar da polissemia da noção de autonomia e centrar-se na sistematização de um arcabouço para um projeto autônomo.

\section{O PROBLEMA DA AUTONOMIA: CONCEITO MORAL E ÉTICO-POLÍTICO}

Para se (re)formular uma noção ético-política relativa à autonomia, parece ser preciso, antes de mais nada, se desvencilhar da polissemia acerca do conceito.

De modo geral, a noção de autonomia se desenvolve como projeto da modernidade paralelamente à redução do poder teológico-político, acompanhando o aumento da liberdade política e a afirmação do domínio da razão pelo homem. É, sobretudo, no bojo do movimento iluminista, que o homem passa a se afirmar como um ser autônomo e universal, dotado de uma razão atuante sobre a sociedade e a natureza.

De modo geral, a autonomia é definida nos dicionários filosóficos como "capacidade" individual para autodeterminação e autogoverno (ver verbete Internet Encyclopedia of Philosophy). Com essa conotação, o conceito tende a situar-se no âmbito da consciência e da filosofia moral. Embora a etimologia da palavra guarde raízes na Grécia antiga (auto-nomos - aquele que se dá a própria lei), a noção de autonomia está fortemente associada ao pensamento moderno, sendo marcada particularmente como uma empreitada iluminista que tem o pensamento de Kant como o vértice da formulação mais acabada.

Como se sabe, Kant busca alguns fundamentos na ideia de Rousseau de liberdade moral como domínio sobre si próprio, que está associada à liberdade 
civil e à capacidade legisladora. Mas essa ideia rousseaniana desenvolve-se também entre os românticos, que concebem a autonomia como aquilo que dota o indivíduo de autenticidade. Desse modo, se é mais autônomo quanto mais autêntico se puder afirmar.

Sucintamente, Kant concebe a autonomia moral como a autoridade sobre suas próprias ações e orientações, à procura do afastamento da menoridade do homem (ou do povo) submetido historicamente a um poder tutelar. Essa tutela dá lugar ao governo de si pelos outros, a obediência conjugada à ausência de raciocínio e falta de pensar por conta própria. Para isso, a razão legisladora faz prescrições de leis morais traduzidas invariavelmente por máximas ou princípios universais de conduta (por isso não são nem arbitrárias nem particulares), ou seja, os imperativos categóricos, dotados de normas não individualmente e sim universalmente válidas, bem como deontológicas.

No opúsculo seminal "O que é o esclarecimento?", Kant mostra como a autonomia diz respeito tanto a um indivíduo que, comodamente, mantém-se em estado de menoridade sob a tutela de algo ou alguém que o diga o que fazer (seja um livro, seja um pastor, seja um médico), quanto a um povo que deve obedecer às leis dadas a si mesmo. Não se trata, portanto, de ser obediente a uma lei externa ou a um dogma religioso. A busca por uma maioridade se estabelece por meio do dever e da obediência, que devem se referir à lei moral formulada por si mesmo e imposta a si mesmo, sendo guiado por máximas consideradas universais. Percebe-se, assim, como a noção de "autodeterminação" vai aos poucos se aproximando de ideias associadas ao campo da moralidade em que conteúdos deontológicos são centrais. Indubitavelmente, os imperativos kantianos sintetizam a forma mais acabada, apurada e avançada da formulação moderna de autonomia.

Referência maior no iluminismo e na modernidade, a teoria de Kant oferece esteio fundamental para se pensar o tema da autonomia, a partir da qual se derivam vertentes teóricas de natureza diversa. Na fonte kantiana bebem, por exemplo, pensadores contemporâneos como John Rawls, na vertente liberal, e pensadores do marxismo heterodoxo, como Cornelius Castoriadis. Assim, a noção de autonomia tem participação importante na gramática liberal, a saber, uma autonomia como princípio da individualidade e ausência de coerção sobre a capacidade de autodeterminar-se. Com a visão romântica, a autonomia passa a ser fortemente associada à ideia de autenticidade. Essas bases engendram, em graus distintos, a perspectiva prevalecente de autonomia, tendo como perspectiva um indivíduo autônomo como racional-independente-autárquico. 
Por vezes, o problema da autonomia é definido como um problema, em primeiro plano, pessoal.

Essa perspectiva compõe determinados postulados que, como sustenta Castoriadis, são desenvolvidos desde Platão até o liberalismo moderno. Segundo ele, é como se houvesse uma ordem "racional" do mundo a ser apreendida, uma "ontologia unitária" que dissimula a visão de que "a história humana é criação” (CASTORIADIS, 1987c, p. 293). A partir do século XVIII (com exceção de um movimento radicalmente crítico, democrático e revolucionário contestatório do imaginário e das condições instituídos), o ressurgimento de um pensamento crítico e liberador está, de modo em geral, sob a influência de uma "metafísica racionalista" que invoca uma razão (quer receba o nome de natureza ou de Deus) como fundamento último e extra-social da lei:

A dessacralização da instituição já foi consumada pelo capitalismo desde o século XIX. O capitalismo é um regime que corta virtualmente toda relação entre instituição e uma instância extra-social. A única constância que ela invoca é a Razão, à qual dá um conteúdo bastante particular. Há, sob este ponto de vista, uma ambiguidade considerável nas revoluções dos séculos XVIII e XIX: a lei social é apresentada como obra da sociedade e, simultaneamente, supõe-se que ela está fundada sobre uma "natureza" racional, ou uma "razão" natural ou transhistórica. E, por fim, esta continua sendo também a ilusão de Marx. Ilusão que é, ainda, um dos disfarces e das formas de heteronomia: quer ela nos seja ditada por Deus, pela natureza ou pelas "leis da história", a lei nos é sempre ditada. A ideia de que existe uma origem e um fundamento extra-social da lei é uma ilusão. A lei, a instituição, é criação da sociedade, todas as sociedades são autoinstituídas, embora até aqui elas tenham assegurado sua instituição instituindo uma origem extra-social para si mesmas e para sua instituição. Aquilo que chamo de autoinstituição explícita - o reconhecimento pela sociedade de que a obra é sua - não implica absolutamente um caráter "frágil" da instituição ou das significações que esta encarna. (CASTORIADIS, 1987b, p. 258)

Com efeito, acrescenta-se que nesse contexto a exigência de autonomia por parte de indivíduos resulta em critério para formas de dominação que exercem clivagem entre os que sabem se governar e os que não sabem se governar, entre aqueles que devem governar e os que devem ser governados. Esse constitui um pensamento que aponta, sobretudo, nas "massas" toda forma de menoridade, de dependência econômica ou de inabilidade cognitiva, servindo desde a teoria do voto censitário até às bases do sistema representativo. Essa visão tende a afirmar a incapacidade de alguns ou mesmo das massas para a autonomia, a democracia 
tendendo a ser entendida como reino da heteronomia do demos, a ser administrada por lideranças de tipo pastoral, em vez de ser entendida como prática inarredável de um projeto de autonomia da sociedade.

Uma "sociedade autônoma" só é possível em uma sociedade radicalmente democrática? Uma "sociedade autônoma não pode ser instaurada senão pela atividade autônoma da coletividade" (CASTORIADIS, 1999, p. 83). Como argumenta, o gérmen da essência política da Grécia antiga está no "processo histórico instituinte, ou seja, a atividade e a luta que se desenrolaram em torno da mudança das instituições, a auto-instituição explícita (ainda que permaneça parcial) da pólis enquanto processo permanente [...]" (CASTORIADIS, 1987c, p. 293). Castoriadis vê isso ocorrer desde a constituição dos cidadãos espartanos como homoi (semelhantes) até o questionamento regular da instituição da democracia pelo demos.

Por isso, um projeto de autonomia estabelecido no campo ético-político tende a se colocar a favor da construção de uma sociedade em frequente ou constante processo de desenvolvimento de formas de autogoverno, capaz de deter o controle de sua própria vida, diferentemente de uma sociedade que é simplesmente governada. Certamente que esse é um processo sempre errático, fugidio e, de certa maneira, descontínuo. Um projeto nesses moldes busca, na verdade, pensar como se pode reviver ou experimentar mais intensamente o movimento de auto-institução da sociedade, revigorando esse poder criador de auto-instituição.

A autonomia torna-se, assim, indissociável do movimento de autotransformação da sociedade e, portanto, da democracia, do processo de dar-se a si mesmo a própria lei. "Se quisermos ser livres, devemos fazer nosso nomos. Se quisermos ser livres, ninguém deve poder dizer-nos o que devemos pensar" (CASTORIADIS, 1992, p. 138). Ao contrário, as sociedades são estruturadas para a conservação e reprodução de suas normas, de suas leis, de suas instituições, o que conforma sua heteronomia.

A questão está em como superar a supremacia das formas de dominação que caracterizam a sociedade heterônoma, deixando a condição de passividade e pura expectativa, sem simplesmente inverter os polos da heteronomia como no paralogismo do cordeiro revelado por Nietzsche. Tendo como premissa a descontinuidade do tempo histórico, trata-se de pensar como se pode reviver ou experimentar mais intensamente o movimento de auto-instituição da sociedade e, para isso, revigorar o poder criador de auto-instituição. 


\section{PARA UM PROJETO DE AUTONOMIA: APORTES DO SPINOZISMO}

Ao tematizarmos a autonomia na teoria de Spinoza (1632-1677), algumas dificuldades aparecem. Inicialmente é preciso frisar que abordar o tema da "autonomia" em Spinoza implica, no mínimo, em um anacronismo, embora o pensador figure brevemente em verbete de dicionários filosóficos. Como se sabe, a rigor, o pensamento em torno desse conceito se desenvolve mais tarde, tendo como referência maior Kant (1724-1804). Uyl nota que o termo "autonomia", usado em um sentido político, é reconhecido pelo Oxford English Dictionary tendo uso no século XVII. Todavia, a ocorrência do termo nesse tempo não é expressiva. Citando o artigo de David A. J. Richards, Uyl identifica os primórdios do uso do termo mais ou menos no período da Guerra Civil inglesa (1642-1645), sendo sua aplicação filosófica localizada extensivamente entre Rousseau e Kant. O termo também não aparece no rol de conceitos spinozanos, embora alguns intérpretes estabeleçam equivalência entre a expressão latina sui juris (utilizada por Spinoza no Tratado Político) e o termo grego auto-nomos.

Cabe perguntar, então: de que maneira é possível abordar o tema da autonomia em Spinoza, sem ignorar o anacronismo do uso do conceito e a própria ausência do termo em sua filosofia?

De modo contrário a esse obstáculo, é comum notar estudiosos mencionarem o pensamento de Spinoza como uma filosofia da autonomia. Bernard Rousset (estudioso de Spinoza, Kant e Hegel), pelo menos, assim a qualifica. Ele defende, em La Perspective finale de l'Éthique et le problème de la cohérence du spinozisme: lautonomie comme salut, que a autonomia tratada no pensamento de Spinoza é "mais rica e rigorosa" do que a autonomia exaltada no romantismo e no iluminismo. Ao lado de estudiosos como Rousset, aparecem pesquisadores como Jonathan Israel, para quem o spinozismo é considerado expoente de um pensamento iluminista radical entendido como conjunto revolucionário de ideias que lança as bases da igualdade, da democracia e da universalidade na modernidade, a ser marcada pelas revoluções intelectuais e políticas do século XVIII.

Parece pertinente, tendo isso em vista, pesquisar no interior do spinozismo questões relativas ao tema da autonomia. Essa filosofia é apontada como radical porque, além de confrontar a monarquia e o poder teológico, propõe basear a democracia na potência de uma multidão. Na verdade, essa democracia consiste 
em uma verdadeira democratização que, grosso modo, designa uma força motriz subjacente a todos os regimes políticos. Todo pensamento político de Spinoza parece incitado pela seguinte proposição: nada é mais insuportável aos homens que serem submetidos a seus iguais e serem dirigido por eles (TTP V e XVII e TP, VII, 5).

A autonomia baseia o auto-governo, a auto-determinação e o autodirecionamento em atos de decisão tomados por meio de processos de reflexão, exame crítico e deliberação racional, sendo essas ações produtos de nossas vontades, em vez das vontades de outra pessoa ou mesmo de fator externo qualquer. Os termos dessa linguagem não estão presentes em Spinoza, no entanto, encontram-se outros elementos fundamentais não necessariamente para concepção de "conceito de autonomia", e sim para um "projeto de autonomia”. Um projeto de autonomia que se pretende inarredável de um movimento de democratização tem muito a pensar a partir da investigação de teorias como a de Spinoza, em que as massas ou a multidão são divisadas mais pelo seu caráter de potência do que de impotência ou passividade.

$\mathrm{Na}$ linha da teoria spinozista, trata-se de pensar não somente como as forças sociais multitudinárias são exteriormente dominadas, mas como elas logram resistir à dominação, subtrair-se à heteronomia, evitar a determinação por causas externas, reduzir a opressão e escapar à servidão. Para além das discrepâncias temporais e terminológicas, a questão maior, no entanto, está, como argumenta Uyl, na natureza de sua filosofia. A tarefa seguinte é, portanto, a de investigar aportes teóricos relevantes para um projeto de autonomia indissociavelmente democrático, capaz de revigorar o movimento de auto-instituição obnubilado na prática política.

\subsection{RAZÃO LEGISLADORA E RAZÃO AFETIVA}

A razão constitui, na história do pensamento ocidental, condição cognitiva imprescindível para caracterização da autonomia. Com efeito, constitui um estatuto à parte a visão sobre a relação da razão com as paixões e as outras formas de conhecimento. Uma das visões mais emblemáticas acerca disso é a crítica da razão prática de Kant. A partir dela afirma-se a necessidade de um projeto em que o indivíduo não se torne refém da experiência marcada por desejos, paixões, impulsos e inclinações. Somente dessa forma, a razão pode adquirir condições adequadas para estabelecer fundamentos em prol da concepção de leis práticas universais. A autonomia, para Kant, passa justamente 
pela prescrição de uma razão legisladora, sendo o indivíduo capaz de raciocinar por si mesmo.

A relação entre razão e paixão é, frequentemente, contraditória. Em termos kantianos, os indivíduos até são capazes de conceber, a priori, uma ideia da razão prática enquanto afetados pelas inclinações. O problema, todavia, é que os indivíduos não são dotados de força suficiente, isto é, de vontade necessária para efetivamente exercer o que prescreve a razão, sucumbindo aos instintos e às paixões. A formulação do imperativo categórico como lei moral apresenta-se, justamente, como forma de superar tal limitação. Ao considerar a vulnerabilidade da vontade e o livre-arbítrio falho, o projeto kantiano tem dificuldades de contemplar em sua razão prática uma afetividade prática. Essa abordagem não se restringe de modo algum ao kantismo. A precedência da razão sobre as paixões caracteriza as fileiras da tradição racionalista do pensamento ocidental.

A teoria do conhecimento de Spinoza oferece ao pensamento autônomo visão um pouco distinta. Crítica da noção do voluntarismo ou da vontade como livre-arbítrio, a filosofia spinozana sustenta que o indivíduo pode orientar a si mesmo pela razão, sendo impossível ignorar, suprimir ou se desvencilhar do terreno originário da realidade afetiva. A razão apresenta não só uma base afetiva, bem como não apriorística e, por consequência, relacional.

A começar pela base não apriorística: para que haja compreensão pela razão muito raramente se pode prescindir da experiência ou do mundo sensível. A formação de conhecimento racional tem início quando o corpo humano entra em contato com as coisas, afetando e sendo afetado por afecções de vários outros corpos. Nesse processo, a mente humana também afeta e é afetada pelas ideias desses corpos exteriores, decorrendo daí modificação em nossa mente. Isso constitui um processo contínuo de modificação, em que imagens e marcas são deixadas no corpo e na mente. Esse processo envolve conhecimento mais ou menos adequado (racional ou imaginativo) da essência e da natureza das coisas externas e da própria constituição do corpo e da mente. Se, por um lado, Spinoza explica em sua correspondência (carta X) que "(...) a experiência nunca nos ensina a essência das coisas (...)”, por outro, o filósofo assinala que a dedução de algo “(...) a partir unicamente de noções intelectuais se requer muitas vezes um longo encadeamento de percepções [experiências], além duma extrema prudência, perspicácia e contenção, tudo qualidades que só muito raramente se encontram nos homens" (TTP, cap. IV, p. 185). Como bem sintetiza Ferreira (2014), há um duplo jogo entre experiência e intelectualismo, 
estando bem marcada a distância entre um intelectualismo puro e um empirismo puro.

A razão apresenta uma base afetiva. Antes de tudo, os gêneros de conhecimento não são considerados estanques, a divisão em imaginação, razão e intuição constituindo meramente uma abstração, método do filósofo para organizar o pensamento acerca do processo cognitivo. A elaboração intelectual própria à razão deriva do terreno originário e ordinário da imaginação. ideias relativas à imaginação se caracterizam por serem confusas e por mutilarem efeitos de causas. A imaginação é considerada um gênero de conhecimento inadequado e mal concatenado. Mas ainda assim, ela constitui um gênero de conhecimento e, sobretudo, um gênero constituinte da nossa condição cognitiva imediata e primordial. A partir dessa condição, as ideias da mente imersa na inadequação se movem em um percurso errático e por vezes aleatório por meio de associações. Esse processo mental resulta em uma parte ativa, favorecida contingencialmente por um ambiente alegre fortalecedor da potência. Desse modo, a mente torna-se apta a perceber o que há de comum entre o seu corpo e os corpos exteriores, formando assim noções comuns. As ideias claras e distintas se constituem a partir da formação dessas noções. Tratase de um processo praticamente experimental, nem especulativo nem voluntário. Nota-se que nessa visão a razão não se caracteriza como faculdade, isto é, como capacidade natural ou adquirida.

Nesse processo, vale destacar que: se não há processo intelectual sem experiência, também não há processo intelectual sem experiência afetiva. Afetos ou paixões são eles próprios definidos como "passagens vivenciadas" ou "variações contínuas" entre uma afecção e outra, um estado e outro, uma imagem e outra. $\mathrm{O}$ afeto implica tanto para o corpo quanto para a mente aumento ou diminuição da potência (DELEUZE, 2002). Afetos constituem, portanto, um índice da variação da potência: se alegres, aumentam a potência; se tristes, entravam a potência. Os afetos são considerados paixões, isto é, dizem respeito à nossa passividade. Isso porque eles provêm do encontro exterior com outras coisas existentes, explicando-se "pela natureza do corpo afetante e pela ideia necessariamente inadequada desse corpo (...) Tais afetos são paixões visto que não somos a sua causa adequada”, sintetiza Deleuze (2002, p. 57), citando Spinoza (E, II, def. 2). A passividade impera até a potência de agir do corpo e de pensar da mente crescer a ponto de conceber a si mesmo e às suas ações adequadamente. Por esse motivo, os afetos consistem em um regime de conhecimento, um modo de pensar. A razão tem uma base relacional: quanto 
maior a exposição à diversidade de corpos exteriores, maior produção de associações, maior possibilidade de concepção de noções comuns e mais chances de concebermos as coisas racionalmente.

A rigor, é inapropriado dizer que a razão pode submeter ou dominar afetos e paixões. Fazer-se conduzir pela razão não depende de uma vontade forte ou de um livre arbítrio determinado. Orientar-se a si mesmo, desvencilhando-se da fortuna e da força da contingência, depende do processo que transforma a passividade em atividade, a inadequação em adequação de pensamento. No projeto ético de Spinoza, a razão pode sim participar efetivamente da geometria afetiva, regulando e moderando os afetos na interação entre eles, a partir de uma tarefa de organização do jogo de afetos. Ao reconhecer a força dos afetos, Spinoza sabe que eles podem imperar sobre ideias racionais, o que configura o indivíduo tomado pela acrasia. Assim, o papel da razão é o de opor aos afetos um afeto mais forte ou contrário e o de produzir algo como uma autoafecção, isto é, fazer originar a partir dela um afeto, chamado de afeto ativo (ou ação). Melhor ainda: a ideia que adequa clara e distintamente a causa do efeito vem, necessariamente, acompanhada de uma alegria, agora na sua qualidade de afeto ativo. "Quando a mente concebe a si própria e à sua potencia de agir, ela se alegra (...) Logo, ela se alegra também à medida que concebe ideias adequadas (..)", define Spinoza (E, III, prop. 58, dem.).

O filósofo oferece uma visada bastante distinta acerca dos campos do conhecimento. A razão, núcleo central da teoria da autonomia, ganha outra natureza. A partir daí, novos fundamentos podem ser experimentados para construção de um projeto de autonomia efetivo. Como formula Balibar, "a base afetiva, não apriorística e relacional da razão em Spinoza leva-o a recusar o âmago do iluminismo", qual seja, o "normativismo que transforma em absoluto, ainda transcendente, a capacidade dos homens de compreender seu poder de produzir o meio de vida que eles produzem, bem como suas leis de organização" (BALIBAR: 1990, p. 8).

\subsection{INDIVIDUALISMO AUTÁRQUICO E TRANSINDIVIDUALIDADE}

Indivíduo e povo são categorias em contradição em parte expressiva do pensamento moderno. Em termos políticos, Rosanvallon evidencia essa aparente "dicotomia" presente na teoria da democracia moderna ao instaurar o povo como soberano coletivo e, portanto, no posto de comando, ao mesmo 
tempo em que sacraliza o indivíduo, com autonomia e direitos valorizados. De um lado, o princípio político que consagra o poder de um sujeito coletivo; do outro, o princípio sociológico que tende a dissolver sua consistência e a reduzir sua visibilidade, formula Rosanvallon. Essa concepção de autonomia individual, importante no desenvolvimento da democracia, torna-se central no liberalismo e, na medida em que individualiza em grau máximo as coisas dotando-as de natureza privada, torna-se também obstáculo para a constituição do comum. Dessa maneira, um mundo de indivíduos tem sido "condição de igualdade" ao mesmo tempo em que problema para a "constituição do comum", sintetiza (Rosanvalllon, 2011). O tecido social assim ordenado politicamente tende ao esgarçamento.

Parece claro que a teoria da autonomia, em boa medida importante no liberalismo, encontra na descrição de Rosanvallon ressonâncias. Da autonomia moral de Kant à autonomia pessoal de teorias mais recente, a ideia de autonomia foi assimilada concomitante a processo de individualização. Os românticos, por exemplo, reagem à ênfase dada à universalidade da razão estabelecida pelo esclarecimento, da qual a filosofia de Kant é a parte mais proeminente, e valorizam a particularidade e a individualidade. Enfatiza-se aí o papel das paixões e emoções sobre a razão e a importância do cultivo de um "eu" único, o "eu" distinto das massas, como se lê em Stuart Mill. Forjada nessas veredas teóricas, a ideia de autenticidade se torna, doravante, inseparável da ideia de autonomia. Pondo de lado o universalismo kantiano, os românticos não definem a questão da autonomia pelo "pensar por si mesmo", mas pelo "ser uma pessoa única". "Para Kant, pensar por si mesmo poderia, se empreendido devidamente, levar a universalização das máximas; para Românticos e existencialistas, bem como para Mill, não existe essa expectativa", afirma Christman (2015). Como sintetiza, estamos diante do "contraste entre conceber autonomia como característica fundamental para a motivação moral e autonomia como auto-expressão e desenvolvimento da identidade prática do indivíduo".

A visão acerca de uma ideia de autonomia segue uma deriva pela qual independência e individualismo atomístico são associados ao seu conceito. Equivale a dizer que, em termos propriamente políticos, esse conceito passa a refletir essencialmente premissas do individualismo, dando peso moral à capacidade individual para se governar e ser autêntico. A autonomia passa a figurar como premissa de apoio, no liberalismo, para afirmar capacidade do cidadão de deliberar e escolher, constituindo-se como pressuposto necessário 
para o funcionamento da democracia, como comenta Christman (2015). Dessa forma, a constituição de uma sociedade autônoma requer a priori um indivíduo autônomo ${ }^{3}$. Pergunta-se: qual o papel que cabe aos indivíduos não autônomos em uma democracia? A democracia deve se restringir ou se reduzir aos indivíduos autônomos capazes de deliberar? Qual é o projeto para os demais não autônomos? A autonomia é uma capacidade ou condição que se "adquire" ou se conquiste individualmente?

O spinozismo apresenta um terreno especialmente fértil por fornecer conceitos para a crítica da lógica autárquica e autossuficiente do indivíduo. Ele identifica um processo de imitação e projeção de afetos e desejos - a "unidade" afetiva em que cada um participa no afeto ou no desejo de outros e que marca a composição de um indivíduo singular. Se há participação de muitos em relação a um afeto, e se há também partilha da potência (conatus, isto é, esforço do ser em perseverar na existência), é inútil pensar os indivíduos como separados em vez de pensarem como "partes de uma coisa singular, cujo conatus [...] é expresso em ambos” (MONTAG, 2005, p. 669). Dessa forma, o filósofo pode afirmar que combinados dois indivíduos da mesma natureza há composição de um indivíduo duas vezes mais potente (SPINOZA, E, IV, 18, esc.; TP, II, § 13). Essa composição, porém, não resulta da soma de potências dos indivíduos, ou seja, não é soma e sim composição - a mesma regra vale para formar a multidão ou a comunidade.

Pelo processo de imitação, comunicação e contágio, os afetos e os desejos individualizam, ou melhor, transindividualizam ${ }^{4}$ os homens (Balibar, 1993). Se o indivíduo expressa singularmente uma potência comum (do Deus-natureza), ou seja, se essa potência é partilhada, isso significa que os afetos e desejos

3 Estudiosos contemporâneos, como teóricas do feminismo, não poupam críticas a esse projeto. Críticas à associação entre atomismo, independência e autonomia tentam reabilitar, em contraste, a noção de "autonomia relacional". Feministas como Sarah Hoagland, por exemplo, é levada a rejeitar a própria ideia de autonomia como valor, porque percebe que esse conceito "encoraja-nos a acreditar que a ligação e o engajamento com os outros nos limita” (HOAGLAND, 1988, p. 144 apud CHRISTMAN, 2015). Martha Fineman apresenta uma crítica dura, indicando necessidade de repensar a concepção de autonomia que embasa políticas legais e governamentais de modo a reconhecer nossa interdependência e a dependência de todos nós da sociedade (FINEMAN, 2004 apud CHRISTMAN, 2015). Estudando as teorias sociológicas e as considerações sobre políticas governamentais e legais, ela mostra as associações históricas e culturais da autonomia com a individualidade e a masculinidade, argumentando a necessidade de reconhecer que o real desenvolvimento humano inclui a dependência.

4 Como esclarece Balibar, ele não é o único a propor uma terminologia para expressar a originalidade de Spinoza. O próprio Balibar já havia proposto a ideia de "ontologia relacional", em preferência à expressão de Matheron (1988) que atribui ao spinozismo um "ego-altruísmo". O termo transindividualidade está presente na teoria de Simondon. 
atravessam todos eles. Assim, para Balibar, "sem que desapareça a ideia de individualidade" (ideia da estabilidade de uma complexidade de corpos), o verdadeiro objeto dos estudos de Spinoza "é o processo mesmo, a rede afetiva que atravessa cada indivíduo, passando e repassando por suas 'partes' e por suas ideias ou imagens" (BALIBAR, 1990, p. 26). Considerar o indivíduo em um isolamento subjetivo é, portanto, um equívoco resultante da ideia fictícia (religiosa e moral) de que o homem se constitui seguindo um livre-arbítrio.

Dessa forma, "a constituição da individualidade e da multidão no imaginário são um só e mesmo problema, um só e mesmo processo" (BALIBAR, 1990, p.27), uma vez que um indivíduo constitui na verdade um complexo de indivíduos mais simples (um indivíduo é, sob certa perspectiva, uma abstração). Essa concepção exige pensar, como frisa Zourabichvili, que "os processos de individuação não tem lugar fora do campo social", sendo "em vão que se constrói mentalmente a sociedade a partir de indivíduos já formados" (ZOURABICHVILI, 1992, p. 152). Em função disso, para ele, a questão da sociabilidade deve ser retomada como uma questão de comunidade, isto é, de composição de relações.

É fundamental, portanto, levar em consideração, ao pensar em um projeto de autonomia, ter sob os olhos um trinômio, qual seja, o processo de imitação de afetos, a transindividualização e o aumento de potência. Nos sistemas heterônomos de dominação, fica claro que o perigo da multidão não é simplesmente "o direito ou potência da massa além da lei e propriedade, mas a transindividualização do desejo e afeto e, portanto, do próprio conatus, em um movimento que transborda e excede a fronteira imposta por rituais e aparatos que nos governam" (MONTAG, 2005, p. 670). Esses desejos e afetos, que não são limitados pelo aparato fundado no interesse próprio e calculável do indivíduo jurídico, estão, como expressa Montag, nas raízes da política. Enquanto há partilha de potência, maior a possibilidade de partilhar a liberdade. Percebe-se como a dinâmica de aumento da potência está no centro da ontologia política de Spinoza. Para Bove (2010, 2012c), o spinozismo não trata de uma lógica da autarquia, e sim de uma "autonomia dinâmica e relacional aberta", na medida em que a aptidão aumentada do corpo remete à multiplicação de sua comunicação com a multidão de outros corpos.

Spinoza propõe um conceito irredutível a "um psicologismo" ou à ideia de "intersubjetividade originária" (Balibar pensa em Fichte), assim como a um "sociologismo" ou à ideia de um "condicionamento dos indivíduos pelas condições sociais de existência" (aqui pensa em Marx). O conceito escapa 
também a antinomias como subjetividade e intersubjetividade, individualismo e holismo (ou organicismo), interioridade e exterioridade. Essa concepção não se molda, igualmente, pelas antinomias do pensamento legal e político, que, como sustenta Montag (2005), imagina uma justaposição de indivíduos isolados, assim como supõe um coletivo, comunidade e povo que legalmente se constitui a si mesmo à semelhança de entidade jurídica.

Cabe lembrar que o indivíduo é compreendido como parte de um todo, no qual tudo, homens e coisas, estão em relação. Conceber a não relação é algo impossível, já que o que existe é um "dinamismo de complexos relacionais". A realidade é uma coisa relacional e complexa, expressão da necessidade do Deusnatureza. Desse modo, para que os homens convenham entre si e formem uma potência superior, não se trata de ligá-los por meio de um cálculo racional, como em Hobbes (AURÉLIO in SPINOZA, 2009), porque na verdade os indivíduos se "transindividualizam" primordialmente (mas não exclusivamente) pela afetividade e pelos desejos. Dessa maneira, podemos pensar que a construção de uma sociedade autônoma, como qualquer outro processo político, é uma construção conjunta sem ponto de partida no indivíduo. Essa é uma construção coletiva e necessariamente multitudinária.

Essa ontologia relacional é diametralmente oposta a todo projeto autárquico. Ela afirma a dinâmica do aumento de potência (conatus), que se refere ao aumento da compreensão da mente e da capacidade de agir do corpo. Por isso, "quanto mais um corpo é capaz, em comparação com outras coisas, de agir sobre um número maior de coisas ou de padecer de um número maior de coisas, mais sua mente é capaz de perceber [...] simultaneamente, um número maior de coisas", e ainda, quanto "mais ações de um corpo dependem apenas dele próprio [...] tanto mais sua mente é capaz de compreender distintamente" (SPINOZA, E, II, 13, esc.). Fica patente a correspondência entre o poder de afetar e de ser afetado de um lado, e a aptidão da mente para compreender, de outro. Como sintetiza Bove $(2010,2012 c)$, o que está em processo não é uma lógica da autarquia, e sim de "autonomia dinâmica e relacional aberta". Essas premissas ontológicas evidenciam como a convivência, o apoio mútuo, a cooperação e a consciência da existência comum pavimentam a via para um projeto de autonomia. Conforme assinala Sévérac, "a autonomia intelectual, para Spinoza, não é autarquia: pensar por si mesmo não é apenas pensar, mas pensar pela necessidade que nos é comum" (SÉVÉRAC, 2009, p. 45).

Nessa perspectiva, a multidão ou as massas só podem ser livres justamente quando reconhecem sua ontologia relacional ou transindividual. 


\subsection{O PROBLEMA DO SUI JURIS}

O binômio sui juris e alterius juris aparece em Ética e em Tratado Teológicopolítico (TTP), vindo no entanto a adquirir maior consistência como noção política em Tratado Político (TP). O termo sui juris tem origem no direito romano, sendo aplicado no âmbito do domínio privado da família, juntamente com alieni juris, sendo o pater familias (pátria potestas) a figura superior. Mas o uso moderno desses termos não segue o significado original da expressão no direito privado romano. Como explica Campos (2005), esse conceito transita da esfera jurídico-privada para a esfera jurídico-pública até ser assimilado como conceito político. O termo sui juris, usado pelos teóricos neorromanos, passa a ser sinônimo de independência e autonomia para os modernos.

Duas questões devem ser explicitadas. Primeiro, Spinoza não utiliza o binômio sui juris/alieni juris, mas sui juris/alterius juris. O filósofo não explica a razão dessa substituição. Esse binômio é apresentado por intérpretes, entre eles Marilena Chauí, como equivalente a noções gregas de autonomos/heteronomos. A expressão é normalmente traduzida como aquele que está "sob jurisdição de si próprio" ou aquele que é "seu próprio senhor" (sui juris) e aquele que está "sob jurisdição de outrem" ou que "tem outro como seu senhor" (alterius juris). Segundo, Spinoza não emprega o mesmo sentido dos modernos, isto é, "não se limita a copiar para os seus textos políticos uma expressão latina muito em voga no seu tempo que aplique às reflexões jurídico-políticas uma clássica percepção de autonomia e independências individuais (...)” (CAMPOS, 2005, p. 60).

A concepção de liberdade consiste na livre necessidade e não na arbitrariedade, na discricionariedade. Uma coisa é livre quando só existe pela necessidade apenas de sua natureza, sendo por si só determinada a agir. É necessária ou coagida a coisa que é determinada por outra a existir e a operar de certa e determinada maneira, como afirma Spinoza em Ética (E, I, defin. VII). O indivíduo não chega a operar (ou mesmo existir) por consequência causal de sua própria existência. Ele somente existe enquanto está em uma relação com o exterior, isto é, sempre em uma relação de potência. Para cada coisa singular é dada na Natureza outras mais potentes e mais fortes (E, IV, axioma). A rigor, somente Deus, isto é, a natureza (Deus sive Natura) é realmente livre. Dessa maneira, na filosofia de Spinoza, o indivíduo parece ser mais coagido do que livre. Ademais, fica claro que não pertence à potencia de um só homem agir sobre a relação causal de tudo aquilo que neutraliza as coações externas.

Bastante complicado, portanto, é afirmar que ao utilizar a expressão sui 
juris Spinoza elimina totalmente a necessidade de dependência externa (CAMPOS, 2005). Esse aspecto importante fica muito claro quando se percebem as múltiplas vezes que Spinoza afirma em Tratado Político a necessidade de cooperação, de auxílio mútuo e de constituição de um direito comum. Por isso, se o leitor atentar rigorosamente para as expressões utilizadas por Spinoza nos parágrafos de TP referentes ao binômio sui juris/alterius juris, é possível resgatar maior coerência ao conjunto de sua obra.

Veja-se. Campos chama atenção para essa passagem, em que o filósofo afirma que "estão maximamente sui juris aqueles que maximamente se distinguem pela razão e que maximamente são por ela conduzidos e, por isso, chamo totalmente livre ao homem na medida em que é conduzido pela razão" (TP, II, 11, grifo nosso). Há aqui uma gradação. Assim, os homens podem ser "maximamente" conduzidos pela razão, o que significa que podem ser também "minimamente" ou mais ou menos conduzidos por ela. Da mesma forma, eles podem ser "totalmente" livres ao usar retamente a razão ou então "parcialmente" livres. Essas construções linguísticas sugerem a existência de graus distintos de sui juris, o que afasta a expressão de um uso estritamente jurídico.

Muito mais do que isso: a existência de uma gradação de sui juris sugere, como ressalta Campos (2005), ser possível afirmar que alguém é mais ou menos sui juris. Portanto, imaginação e razão não são gêneros de conhecimento estanques, aquele conduzido unicamente pela razão no grau máximo e unicamente pela imaginação em grau mínimo. O parágrafo forja, por assim dizer, uma abstração, todavia muito útil para se pensar o quanto os indivíduos podem estar aquém da liberdade. Como ressalta Campos (2005), existem graus de sui juris, assim como existem graus do conhecer. Dessa forma, Spinoza expulsa qualquer dicotomia, estabelecendo um processo de autonomização ou libertação permanentes, no lugar de um estado de autonomia e liberdade fixos. Campos bem acrescenta que essa consideração ganha mais sentido conforme se nota que não há incompatibilidade entre sui juris e alterius juris, passando a ser compreendido como uma gradação progressiva.

A definição de sui juris em Tratado Político não corresponde a uma noção de independência, nem exclui necessariamente a dependência. No pensamento político de Spinoza, o indivíduo não prescreve sozinho, mais em comunidade, suas normas de conduta. A vida política consiste em uma composição da potência individual com a potência multitudinária, de modo que o indivíduo se potencializa justamente na partilha dessa potência superior. Como define 
Spinoza, o homem que se conduz pela razão é mais livre na sociedade civil, onde vive de acordo com leis comuns, que na solidão, onde obedece apenas a si mesmo (E, IV, prop.73). Se os homens, contudo, se conduzissem pela razão, eles seriam livres e formariam uma comunidade de homens livres que necessitam uns dos outros, mutuamente. Os indivíduos racionais e livres não se encerram em si mesmo. Ademais, em última instância, a comunidade racional não é uma comunidade política, uma vez que homens livres não necessitam de instâncias de mando jurídico-políticas (Estado), que prescrevam como se conduzir (ver carta XIX).

\subsection{RECURSOS DE AUTORREGULAÇÃO}

$\mathrm{Na}$ construção de formas pelas quais a multidão pode ser livre, o spinozismo resgata em certa medida os recursos de Maquiavel, em sua célebre fórmula: observar os meios de que se serve um príncipe "animado pela única paixão de dominar" (TP, V, 7) para constituir sua soberania e conservá-la; e, ao mesmo tempo, os meios pelos quais o povo, movido pelo desejo de não ser "comandado nem esmagado pelos Grandes" (na expressão de O Príncipe, IX) deve usar para consolidar e preservar sua liberdade (teses em O Príncipe, IX, 2; Discurso, I, 4). A propósito, de acordo com o "agudíssimo" Maquiavel, como citado por Spinoza, a multidão constitui fundamento mais seguro do que os Grandes para o ordenamento político (Estado), e é sobre ela que se deve depositar com mais segurança a guarda de liberdade. Tanto em Spinoza quanto em Maquiavel encontra-se o resgate das formas de associação e cooperação das forças sociais para assegurar a liberdade.

Ao reconhecer a superioridade da "multiplicidade" da multidão (múltiplas singularidades), Spinoza divisa uma potência (multitudinis potentia). Essa potência consiste no "esforço" de autoafirmação da vida, de persistência na existência, de conservação de si e de resistência do ser a formas mortificantes de destruição e dominação. Essa potência é traduzida em termos políticos como direito natural, que não é suprimível pelo direito comum civil. Dessa forma, o direito natural é concebido como coextensivo à potência, ao mesmo tempo determinando e excedendo o ordenamento jurídico-político instituído.

Para Spinoza, a adequação entre vontade do soberano (poder instituído) e vontade da civitas (poder instituinte) produz uma tensão constante entre multidão e Estado, na qual opera um regime de guerra, latente ou manifesto, que reina necessariamente no cerne do mundo comum. Esse regime é movido 
pelo desejo que tem cada um de não ser dirigido por seu igual-semelhante. Como assinala Bove (2002), é o modelo maquiaveliano de guerra - e não o hobbesiano de contrato - que se impõe no cerne da análise política spinozista. Em termos políticos, uma das formas de garantir essa liberdade é desenvolver dispositivos de contra-poderes (institucionalizados ou não), fundados sobre um "direito de guerra", em que seja possível "expulsar progressivamente desses Estados aquilo sobre o qual são historicamente fundados", a saber, a dominação do homem pelo homem, de um mundo comum por outro, dominação essa justificada com frequência pela função de experts ou profissionais políticos.

É interessante observar como é operada, no pensamento de Spinoza, a função autorreguladora de certos mecanismos como, por exemplo, a indignação. Antes de ser um pecado da multidão, a indignação é índice de pecado da Cidade, ou seja, de uma organização heterônoma que faz coisas que podem ser causa de sua ruína e não observa as leis naturais, o direito natural, isto é, a potência (TP, IV, 4), as leis e regras defendidas não pelo direito civil, mas pelo direito de guerra (TP, IV, 5 ).

Comentadores notam que Spinoza faz da indignação da multidão (ou simplesmente o medo de tal indignação), em vez da lei ou do costume, o principal freio sobre o poder abusivo do soberano ou do Estado. Na visão de Negri e Deleuze, lê-se aí um antijuridismo, ou seja, a subordinação da lei à força da potência ou a negação de manter qualquer noção de regra da lei separada de seu poder causal. Nota-se que, no cerne da conservação da liberdade, encontrase a resistência à dominação expressa em uma relação de constante tensão com o Estado. Ao reconhecer em Maquiavel um "partidário da liberdade", Spinoza entende que seus conselhos são salutares para conservar a liberdade e tende a incorporá-los em função de um projeto de libertação, o da multidão livre ou libera multitudo (TP, V, 6 e 7).

Como ocorre a libertação da multidão e como se torna a multidão livre parece ser ainda algo a ser explorado na obra de Spinoza. Zourabichvili chega a considerar essa como uma questão "enigmática". Sobre tal questão, se pergunta: a noção de multidão livre designa um estado incondicionado da multidão, momento originário em que a vida dessa multidão não permanece ainda regrada pelas instituições, ou ao contrário, seria a liberdade dessa multidão efeito da instituição do Estado?

A despeito das lacunas, é importante pontuar que a multidão comporta uma lógica de coalização e conveniência de suas partes implícita na fórmula "potência igual a direito", segundo a qual dois indivíduos formam uma potência 
maior do que somente um (TP, II, 13). A partir daí, torna-se nítido que o apoio mútuo ou a vida em comum é a condição para sustentar a vida e cultivar a mente, fazendo com que o spinozismo forneça ferramentas 1) contra o individualismo atomista, sendo a autonomia ou a potência do indivíduo não reduzida, e sim alargada pela constituição da sociedade civil; e 2) contra o holismo, a soberania ou potência do Estado não é reduzida, mas alargada com o aumento da autonomia dos cidadãos.

\section{4 À GUISA DE CONCLUSÃO}

Este ensaio constitui um esforço de aproximar-se do pensamento acerca da autonomia. Em um primeiro momento, tenta-se extrair alguns de seus fundamentos, localizar suas referências maiores e encontrar suas raízes teóricas na tradição moderna. Lança-se uma visão panorâmica sobre a teoria de Kant, a mais apurada e acabada teoria moderna em relação à autonomia, mencionando as perspectivas românticas e liberais em torno do assunto. Trazendo à baila a leitura de origem kantiana de Castoriadis, busca-se estabelecer a proposição de um projeto de autonomia como inarredável do processo de democratização da democracia. Com esse intuito, resgata-se Spinoza não como um pensador da teoria da autonomia, mas como um pensador que oferece insumos teóricos distintos da tradição, capazes de conformar um projeto de autonomia não restrito à abordagem filosófica e epistemológica do problema, mas sobretudo política e social; que oferece também algumas ferramentas teóricas que ajudem a montar um projeto de autonomia inarredável de uma democratização da democracia.

A partir de uma circunscrição do aparato conceitual do pensador, algumas ferramentas são brevemente apresentadas ao longo do texto, como a noção de uma razão afetiva, relacional e não-apriorística. Outra noção considerada chave para reflexão em torno de um projeto de autonomia, qual seja, a de transindividualidade, é aqui exposta em contraponto a um individualismo atomista, revelando que a individuação não é um processo de produção de indivíduos independentes - a própria ideia de indivíduos constituindo uma mera abstração. A noção de esse sui juris, traduzida geralmente como "estar sob a jurisdição de si próprio/ser seu próprio senhor”, constitui um conceito político ainda a ser melhor esmiuçado. A abordagem apresentada neste texto permite fazer alguns apontamentos preliminares acerca desse termo ao qual se estabelece equivalência com o termo autonomia: ser seu próprio senhor não é 
uma condição permanente e, sim, uma gradação ou talvez um processo que dificilmente pode ser mensurado ou comparado.

Esse percurso teórico, ainda que inconclusivo, permite, em primeiro lugar, apontar a necessidade de adoção de um nome que traduza o caráter de processo ou de movimento não de uma autonomia, mas de uma autonomização ou mesmo libertação - já que no vocabulário de Spinoza autonomia é termo ausente, sendo "tornar-se livre" a expressão mais presente. Em segundo lugar, possibilita fundamentar um projeto de autonomização segundo o qual o verdadeiro processo de autonomia é procedente de uma relativa dependência. Não aquela que submete os indivíduos a interesses alheios e particulares (pensar em Rousseau para pensar em Kant). Mas aquela espécie de dependência originária, em torno da qual toda a sociedade se estabelece, a do concerto das potências e do apoio mútuo. Dessa forma, se contrapõe à concepção de que a construção de uma sociedade autônoma requer a priori um indivíduo autônomo. Assim, este ensaio apenas acerca-se um pouco mais da questão lançada por Castoriadis: como instaurar uma sociedade autônoma (ou em constante autonomização) em seu movimento democrático?

$\mathrm{Na}$ perspectiva spinozista, o indivíduo/multidão só pode engendrar um processo de autonomização ou libertação quando reconhece em si uma ontologia relacional ou transindividualidade. Em termos spinozistas, isso equivale ao fortalecimento da potência multitudinária, o que conduz a pensar não somente como forças sociais são exteriormente dominadas, mas como elas logram resistir à dominação, subtrair-se à heteronomia, evitar a determinação por causas externas, reduzir a opressão e escapar à servidão. Por isso, sui juris é termo mais presente em Tratado Político que em outras obras do filósofo, situando a autonomização/libertação como princípio realizável na vida política. Desse mesmo modo, a política é vista como desnecessária na vida ética dos sábios, dos racionais ou indivíduos livres. Nesse sentido, entende-se que as noções de razão afetiva, de transindividualidade e de sui juris, bem como as noções de direito de guerra (direito comum) e de indignação (mecanismos autorreguladores do corpo social), apresentam elementos que subsumem a noção de autonomização.

\section{REFERÊNCIAS}

AGUIAR, Thais Florencio de. Demofobia e demofilia: dilemas da democratização. Rio de Janeiro, Editorial Azougue, 2015. 
BALIBAR, Etienne. Ultimi Barbarorum. Spinoza: o temor das massas. Discurso. São Paulo, n.18, p. 7-35, 1990.

BOVE, Laurent. De la prudence des corps: Du physique au politique. In: SPINOZA, Baruch. Traité Politique. Paris: PUF, 2002. p. 9-101.

. Le 'retour aux principes' de l'État de Moïse: Eléments pour une lecture politique et matérialiste de l'enseignement du Christ chez Spinoza. Revista Conatus - Filosofia de Spinoza. v. 4, n.8, p. 73-82, dez. 2010 b.

La prudence du corps chez Spinoza - da la physique à l'histoire. Conferência organizada pelo Departamento de Direito da PUC-Rio. PUC-Rio, 28 ago. 2012c. [No prelo, a ser publicada na Revista Conatus, com tradução de Daniel Nogueira].

CAMPOS, A. dos S. O significado de sui juris na filosofia de Spinoza. Cadernos Espinosanos. 2005, No. XXII. pp. 55-83. Disponível em: http://www.fflch.usp.br/df/espinosanos/ARTIGOS/numero\%2022/andre.pdf. Acesso em: 2 de junho de 2017.

CASTORIADIS, Cornelius. A instituição imaginária da sociedade. Rio de Janeiro: Paz e Terra, 1982.

As encruzilhadas do labirinto 1. Rio de Janeiro: Paz e Terra, 1987a.

. Uma interrogação sem fim. As encruzilhadas do labirinto 2: os domínios do homem. Rio de Janeiro: Paz e Terra, 1987b, pp. 247-267.

A polis grega e a criação da democracia. As encruzilhadas do labirinto 2: os domínios do homem. Rio de Janeiro: Paz e Terra, 1987c, pp. 268313.

As encruzilhadas do labirinto 3: o mundo fragmentado. Rio de Janeiro: Paz e Terra, 1992.

O imaginário político grego e moderno e A democracia enquanto processo e enquanto regime. Em: As encruzilhadas do labirinto 4: a ascensão da insignificância. Lisboa: Bizâncio, 1998.

Socialismo ou barbárie: o conteúdo do socialismo. São Paulo: Brasiliense, 1983.

As encruzilhadas do Labirinto 5: feito e a ser feito. DP\&A, 1999. 
CHRISTMAN, John, Autonomy in Moral and Political Philosophy. The Stanford Encyclopedia of Philosophy (Spring 2015 Edition), Edward N. Zalta (ed.). Disponível em:

$<$ http://plato.stanford.edu/archives/spr2015/entries/autonomy-moral/. Acesso em: 10 de junho de 2017.

CRISTOFOLINI, P. Esse sui juris e scienza politica, Studia Spinozana, 1, Alling, Walther \& Walther Verlag, 1985, pp. 53-71.

DELEUZE, Gilles. Espinosa: filosofia prática. São Paulo, Escuta, 2002.

FERREIRA, Pablo Pires. Meritocracia: uma crítica filosófica sob perspectiva spinozista. Dissertação (Mestrado) - Universidade Federal do Rio de Janeiro, Instituto de Filosofia e Ciências Sociais, Programa de Pós-Graduação em Filosofia, 2014.

FOUCAULT, Michel. O governo de si e dos outros. São Paulo: Editora WMF Martins Fontes, 2010.

KANT, Immanuel. Fundamentação da metafísica dos costumes. São Paulo: Cia Editora Nacional, 1964.

. Resposta à pergunta: Que é esclarecimento? (Aufklärung?). In Leão, Emmanuel Carneiro (org.) Textos Seletos. Ed. Bilíngue. Petrópolis: Vozes, 1985, p. 100-117.

MAQUIAVEL, Nicolau. O Príncipe. Rio de Janeiro: Bertrand Brasil, 2002.

Discursos sobre a primeira década de Tito Lívio. São Paulo: Martins Fontes, 2007.

MONTAG, Warren. Who's afraid of the multitude? Between the individual and the state. The South Atlantic Quartely, 104: 4, Fall 2005. Duke University Press. Disponível em: <http://www.generationonline.org/p/montag_afraid_multitude.pdf>. Acesso em: jan. 2012.

ROSANVALLON, Pierre. La société des égaux. Paris, Seuil, 2011.

ROSENBERG, Arthur. Democracia e Socialismo: história política dos últimos cento e cinquenta anos (1789-1937). São Paulo, Global Editora, 1986.

UYL, Douglas Den. Autonomous Autonomy: Spinoza on Autonomy, Perfectionism, and Politics. Social Philosophy \& Policy Foundation. USA, 2003, 
pp. 30-69.

SÉVÉRAC, Pascal. Conquérir une vie meilleure. Le Nouvel Observateur: Spinoza, le maître de liberté. Paris: Hors-série. n. 73. p.42-45. Jui./Août 2009.

SPINOZA, Baruch. Tratado Teológico-Político. Lisboa, Casa da Moeda, 1988. Ética. Belo Horizonte, Autêntica Editora, 2007. . Tratado político. São Paulo, Ed. Martins Fontes, 2009.

Correspondance. Paris, Éditions Flammarion, 2010.

ZIBECHI, Raúl, CECENA, ESTER, Ana et al. Pensar las autonomías: Alternativas de emancipación al capital y el Estado. 1ª ed.- México D.F.: Sísifo Ediciones, Bajo Tierra, 2011.

ZOURABICHVILI, François. Spinoza, le vulgus et la psicologie sociale. Studia Spinozana, Paris, n. 8, p. 151-169. 1992. 


\section{Autonomía como fundamento de la democratización de la democracia: algumas herramientas teóricas del spinozismo}

Resumen: Este trabajo pretende presentar algunos elementos de la teoría de Spinoza que posibiliten pensar la noción de autonomía, noción esta considerada indisociable, e incluso constitutiva, de la experiencia de democracia, es decir, del proceso continuo de democratización o radicalización de la democracia. Como señala Castoriadis, es mediante la comprensión de la autonomía que se explicita la perspectiva de que las sociedades son normalmente edificadas sobre la base de la ocultación de su auto-institución, comprensión esta que permite establecer la instauración de una sociedad autónoma en su movimiento democrático. Más allá de constituir elementos teóricos en disonancia con teorías más hegemónicas en la tradición moderna (el kantismo, el liberalismo), el spinozismo proporciona herramientas para pensar un proyecto de autonomía no como un problema estrictamente filosófico o epistemológico, sino político y social. Se entiende que nociones como razón afectiva y relacional, transindividualidad de la multitud, sui juris, así como derecho de guerra y indignación (mecanismos autorreguladores del cuerpo social) presentan herramientas teóricas que sugieren una subsunción de la noción de autonomía. Concebida a partir de una especie de dependencia originaria, esa autonomía, o mejor, autonomización/liberación no designa a individuos autónomos como independientes.

Palabras-clave: Autonomía. Democracia. Spinozismo. 